\title{
Mediações entre Periferia, Cultura e Terceiro Setor
}

Mediations between Periphery, Culture and Third Sector

\author{
ISRAEL OLIVEIRA
}

Doutorando do Programa de Pós-graduação em Comunicação e Cultura da Escola de Comunicação da UFRJ. Mestre em Comunicação e Cultura pela mesma instituição. Atualmente é bolsista da CAPES e desenvolve a pesquisa "Em busca do tempo vivido - o uso do saber tradicional nos modelos de gestão socioambiental de reservas extrativistas", sob orientação do Prof. Dr. Mohammed El Hajji.

\section{FAYGA MOREIRA}

Mestre em Comunicação e Cultura (UFRJ).

\section{Resumo}

Refletir sobre a mediação entre a chamada cultura periférica e o mercado de bens simbólicos é o principal objetivo deste texto. Por isso, procuramos construir uma reflexão que envolve sujeitos, produtos e discursos no processo de mediação entre o "morro" e o "asfalto", na tentativa de situar melhor os lugares de cultura que são construídos entre eles. Nessa perspectiva, refletimos sobre a cultura popular em conjunção com a emergência do chamado Terceiro Setor no Brasil, para demonstrar as novas configurações de mediadores sociais que procuram traduzir os excluídos ao tentar inserilos no mercado de consumo.

Palavras-chave: cultura, periferia, terceiro setor.

A partir dos anos 90, a cidade do Rio de Janeiro vem acompanhando a ascensão de vários movimentos culturais surgidos nas periferias principalmente os dedicados à música, como o funk e o hip-hop. Mas não pára por aí: teatro, dança, cinema, artes plásticas, fotografia, literatura, moda e artesanato, entre outros, também estão na ordem do momento da produção cultural das periferias dessa metrópole. Mas, se são periféricas em sua gênese, muitas dessas expressões culturais acabaram incorporadas ao gosto público, junto a vários outros produtos artísticos do chamado "centro" da produção cultural brasileira, e passaram a ser representadas por empresas detentoras da produção, distribuição e controle dos bens culturais e simbólicos nacionais.

Começamos com um exemplo.
No mês de julho de 2005, vários movimentos populares realizaram, na cidade do Rio de Janeiro, uma grande exposição denominada Estética da Periferia. Ao entrar na sala de exposições do Centro Cultural dos Correios, o visitante se deparava com fotografias, mostrando estilos de cortes de cabelos, manequins expondo roupas, reprodução de móveis supostamente utilizados por moradores da periferia, além de alguns ambientes, como botecos, reproduzidos, inclusive, com execução de música ambiente, para dar uma atmosfera daqueles lugares encontráveis nas cercanias da cidade.

O mais curioso da exposição, na verdade, era o desejo dos organizadores de delimitar o lugar desta cultura, chegando a ser chamada, pelo seu curador, Gringo Cardia, de 
${ }^{1}$ As citações foram recolhidas no catálogo da exposição e os autores serão identificados com o nome seguido de EP (Estética da Periferia). "expressões espontâneas que surgem, com vigor, nas periferias dos grandes centros urbanos". O teor do evento era também de " vomitar de uma maneira criativa, tudo que lhe é empurrado como estética ideal comercial imperialista"1. Mas será que diante da complexidade da sociedade contemporânea é possível definir de forma tão dicotômica o que está nas bordas e no centro do caldeirão cultural, se este desejo não for mobilizado primordialmente por uma decisão política ou de mercado? Será que a estética ali apresentada não poderia estar na região mais remotamente periférica como no ponto mais central do difusor cultural da cidade? A pergunta é inevitável: onde fica a periferia?

A primeira resposta parece mais óbvia. É de cunho geográfico e designa um espaço localizado nas cercanias de um "centro", geralmente o coração financeiro de uma metrópole. De acordo com essa lógica, podemos dizer que, no conceito de uma "cidade partida", há um "centro" que pode contar com equipamentos arquitetônicos, infraestrutura urbana (asfalto, água e esgoto), segurança, educação, transporte, tecnologias de arte, cultura e lazer, além de vários serviços privados, e uma "periferia" que dispõe ou não de alguns serviços essenciais, como água e luz elétrica.

Além de oferecerem qualidade de vida e conforto, os equipamentos culturais de um território operam as formas de sociabilidade com o objetivo de "filiar" seus moradores a uma série de redes simbólicas, logo, a sua ausência acarreta sérios problemas, já que os equipamentos sócio-culturais são complementares e, quando um deles falha, acaba prejudicando os demais.

Logicamente, estamos falando de cidades como o Rio de Janeiro, com urbanização europeizada (Paris é tida como cidade modelo), focada na "organização social" de ricos e pobres, mas, principalmente, "centralizada" na facilitação do caminho do capital, oferecendo-lhe as formas mais cômodas de trânsito, com demolição de morros, abertura de túneis, criação de linhas de metrô e ampla oferta de ônibus, para atender às classes alta e média. Com essa urbanização, ao mesmo tempo em que houve a centralização das vias produtivas da cidade, as mazelas sociais foram periferizadas para que as vias afrancesadas pelas reformas urbanas ficassem distantes da população pobre.

A nomeação desses lugares destinados aos pobres pode mudar ao longo da história, mas a inscrição dos sujeitos que os habitam no tecido social acontece por meio de roupagens produzidas "de acordo com o contexto histórico específico", em que o favelado pode ser um fantasma, "um outro construído de acordo com o tipo de identidade de cidadão urbano que estava sendo elaborada, presidida pelo higienismo, pelo desenvolvimentismo, ou mais recentemente, pelas relações autoreguláveis do mercado e pela globalização" (ZALUAR ; ALVITO, 2004, p. 15).

Por isso, além do embelezamento, o conjunto de medidas sociourbanísticas que separou o "centro" da "periferia" promoveu a "gênese da favela" e até hoje marcam as estratégias de civilização e controle, já que os moradores do morro passaram a ser vistos como pessoas que dependem de aplicação de noções de boas maneiras relacionadas à higiene e salubridade dos cortiços. Essas noções se relacionam aos conceitos de civilização vindos do século XVIII, marcados principalmente pelo anseio de promover a formação "humanística do indivíduo, caracterizada 
pelo uso da escrita, pela vida urbana, pela divisão social do trabalho e pela organização política complexa" (SODRÉ, 2005, p. 20).

Além disso, o conceito de cultura, também sistematizado no século XVIII, numa complementação à idéia de civilização, representava "os valores espirituais (seriedade, elevação, refinamento, etc.), que obtiveram valor institucional e social a partir da idéia de progresso" (SODRÉ, Idem, p. 21). Mas, enquanto a cultura se relaciona a um todo generalizado como o "fazer humano", ela também comporta "práticas culturais", que consistem em "transformação de uma matériaprima determinada num produto determinado, transformação efetuada por um trabalho humano determinado, utilizando-se meios de produção determinados" (ALTHUSSER apud SODRÉ, Idem, p. 11).

As práticas sociais são diversas ${ }^{2}$ e, dentre elas, destacaremos a prática cultural, ou seja, "um processo de produção de expressividade simbólica e de distinções sociais pela sensibilidade individual" (SODRÉ, Ibidem, p. 25). As práticas atuantes numa sociedade, argumenta Sodré, "desfrutam de uma autonomia relativa em seu inter-relacionamento, ou seja, cada uma delas dispõe de um espaço estruturado ou sistematizado por regras próprias e com conteúdos claramente definidos" (SODRÉ, Ibidem). É a partir da idéia de práticas culturais que a cultura periférica se constrói como valor tradutor de certos hábitos e práticas que geralmente corroboram certos preconceitos e estigmas.

Com a consolidação da cultura de massa, no entanto, o cultural passa a ser processado industrialmente, dando ao simbólico o status de mercadoria altamente valorizada. Com isso, há uma convergência tecnológica focada principalmente no controle, processamento e difusão dos bens simbólicos, com a máxima eficiência e sinergia produtiva. Para tanto, foram criados diferentes aparatos de comunicação e informação, na tentativa de unificar e controlar as consciências do que é civilizado e culturalmente aceito a partir de padrões de gosto que, a rigor, servem para transacionar narrativas de diferentes naturezas e lugares. É deste cenário da cultura massiva que emergem as brechas para pene-trações das comunidades periféricas nas redes do mercado simbólico.

\section{A centralização da periferia}

A busca da visibilidade almejada pelos bens simbólicos da periferia deve ser apreciada nesta lógica produtiva do capital. E isso acontece porque não há mais um lugar unificado de processamento e fabricação, já que os fluxos produtivos podem estar potencialmente presentes em qualquer lugar. $\mathrm{O}$ preço exigido pelo capitalismo para ser "integrativo" é a flexibilização das regras do Estado, que era o principal gestor cultural, e o direito de assumir as rédeas dos destinos culturais produtivos. Ou seja, para o valor monetário, o valor simbólico é mero detalhe e o destravamento das contenções espaciais vai além do cotejamento de um produto como sendo da periferia ou do centro. Além disso, não se deve perder de vista que a constituição e transformação da cultura se dão num processo de circularidade. Como sugere Bakhtin (1993), ao estudar os diálogos entre a cultura popular e a cultura institucionalizada na Idade Média, as barreiras existentes entre ambas são menos fixas do que se pode imaginar (ou querer).

Assim, a circularidade marca o sentido vivo e "plural" da cultura,
Sodré relaciona as práticas econômica, técnica, política, teórica e outras, dentre as quais a prática cultural. 
para contrapor-se à concepção hegemônica e institucionalizada pelo poder, que procura apresentá-la como uma forma estanque, isolada e intocada pelos sujeitos que a constituem. Desta forma, a circularidade acusa as diferentes trocas, negociações e tensões que marcam os territórios estratégicos e táticos dos grupos sociais organizados num certo sistema social.

Apesar de estarmos analisando práticas culturais contemporâneas inteiramente atravessadas pelas diferentes intervenções que a técnica e a comunicação de massa promulgaram, é possível tomar a idéia de circularidade não apenas para a marcação das trocas entre a cultura popular e a alta cultura, mas também para as circulações de sentido entre os grupos sociais periféricos e os centralizados pelas agências de produção e controle do simbólico.

No entanto, a periferia quer destacar aquilo que é seu, pelas marcações do que é próprio da relação com o lugar (a terra, a espacialidade, a mobília), com o corpo (faces criativas e puras) e com a linguagem (negação do establishment internacional oficialidade), com o objetivo de realizar a "inclusão social de parcelas significativas dessas populações" (CARDIA, EP). Nesse sentido, a dicotomia pode ser tomada como um desejo de estabelecer alguma barreira, capaz de fomentar a transgressão e renovação, fazendo com que os moradores da periferia tomem para si o desafio de reconhecer e valorizar seu patrimônio, ainda que ele não esteja dentro das redes de significação social, da mídia e do mercado.

Mas, ao que se percebe, tais expressões estéticas podem ser geograficamente periféricas, mas culturalmente é quase impossível considerá-las como isoladas dos ditames da cultura aceita e difundida como central (o establishment).

Há, inclusive, uma certa limitação ideológica no estabelecimento do que a periferia assume como sendo seu em termos culturais, pois seus produtos estéticos, ainda que pareçam trazer vestígios das margens da cidade também não deixam de ser um emaranhado de expressões difundidas pelos meios massivos de cultura, principalmente a TV, com o objetivo de capturar os desejos consumptivos desse público. Uma série de calças jeans vestindo manequins na parte central da exposição era um bom exemplo dessa estética periférica capturada pelo mercado.

É nesse sentido que a circularidade nos parece útil para uma apreciação crítica dos produtos culturais contemporâneos, pois ela acusa que as culturas vivem da relação - de oposição ou convergência-, e isso pode acontecer tanto entre os grupos primitivos quanto entre as práticas culturais industrializadas da atualidade.

Com isso, é preciso destacar que, embora estejam surgindo vários movimentos voltados para a promoção da cultura e da arte nas favelas, também está havendo maior aceitação dos produtos oriundos delas por parte do mercado consumidor. Para que haja um encontro entre quem produz e quem comercializa é preciso haver um espaço de mediação, que pode ser definido como o entrelugar (inbetween), conceito cunhado por Bhabha (2005) para determinar o local de encenação das complexidades culturais no pós-colonialismo.

Mais do que dicotomizar o centro da periferia, o entrelugar marca um momento de trânsito, no qual os cruzamentos de tempo e espaço produzem "figuras complexas de diferença e identidade, passado e 
presente, interior e exterior, inclusão e exclusão" (2005, p. 19), que provocam uma sensação de desorientação. Assim, as diferenças não são mais estabelecidas pelas marcas culturais ou étnicas préestabelecidas e fixadas na tradição, mas, sim, numa "negociação complexa, em andamento, que procura autoridade nos hibridismos culturais que emergem em momentos de transformação histórica" (BHABHA op cit, p. 21).

De fato, o hibridismo que, no póscolinialismo, saiu do campo da biologia para dar conta das transformações socioculturais e políticas, reflete bem a mediação entre os "diferentes", localizados principalmente nas grandes metrópoles, envolvendo embates entre: identidades ou origens diferentes dos sujeitos (ameríndia, latina, européia etc.), temporalidades (pré-industrial, moderna, tecnológica etc.) e ebulição entre as fronteiras da cultura popular, erudita e de massa (PRYSTHON, 2003).

Se o entrelugar e o hibridismo podem oferecer partidas para o estudo das culturas periféricas, o multiculturalismo aparece como locus de sua emergência. Pelo discurso do multiculturalismo, a cultura central consegue perceber a cultura periférica e integrá-la na rede de consumo simbólico da metrópole, na qual, como apresenta Prysthon, a "diferença torna-se ponto de partida para a integração ao modelo capitalista global, especialmente em relação aos bens culturais".

Portanto, a ascensão da periferia pode até coincidir com novos avatares socioculturais de seus sujeitos, mas também, e sobretudo, é fruto de uma "conveniência econômica", que encontra em seus produtos distintivos simbólicos comercializáveis. Assim, a "conveniência social", dirigida para a melhoria sociopolítica dos povos, após a retirada estratégica do Estado do direcionamento sociocultural das nações (YÚDICE, 2004), passa a ser uma contrapartida conseqüente deste processo.

Por esta contrapartida, o mercado "sugere" que a periferia se "socialize", afinal o periférico também é sinônimo de pobreza e, além da tradução simbólica de hábitos e costumes, a prática cultural transformou-se numa espécie de "capital ou bem simbólico" que tem a função de resolver os mais variados problemas sociais e, sobretudo, dinamizar as relações entre o que resta do Estado e as populações, sem perder de vista a promoção do capital. Chegou-se a elaborar uma espécie de cidadania cultural, para com isso garantir uma "quantidade mínima" de capital simbólico para as populações menos favorecidas.

O levante cultural da periferia não apenas produz bens culturais que possam entrar no mercado do consumo, que é a face mais visível da inclusão social, como também articula outras formas de participação social:

Cada conquista se contrapõe,
todavia, à constatação de um
novo leque de desafios: da
ocupação do mercado de
consumo à capacidade de
influir em escala no processo de
inclusão social; do domínio
efetivo dos espaços públicos à
consolidação de estruturas que
não sejam erigidas em torno de
interesses personalistas e
hierarquizados; da necessidade
de apoio não assistencialista à
democratização do acesso às
fontes de recursos públicos e
privados. (EP ${ }^{3}$ )

Desta forma, a periferia, além de ser um lugar, é uma categoria distintiva que oferece "novidade"
3 Texto do catálogo da exposição Estética da Periferia não creditado a nenhum autor. 
para a evolução do capital, daí a disposição para a socioeconomia atual, na qual o excluído emerge como promotor de um antropofagismo entre o simbólico oficializado (e comercializável) da cultura central e assimilado pela cultura periférica. Daí, emergem produtos que são promovidos como portadores de ebulições sociais para a fruição da cultura popular, mas também necessárias à oxigenação do capital e à hegemonia dos gostos das classes dominantes.

Nesse atual entrelugar sociocultural brasileiro, ao exemplo do Modernismo de 1922, a periferia parece portadora de uma disposição para, ao invés de endossar um velho olhar antropológico (os estereótipos de pobreza e fragilidade cultural da favela), lançar mão de um espírito antropofágico (afirmação das diferenças e da cultura local), que seja capaz de transformar a realidade econômica dos moradores (principalmente os jovens), por meio de práticas culturais. Para operacionalizar essa transformação, no entanto, entram em cena novas práticas e novos atores sociais.

\section{A cultura do social}

A prática cultural que busca

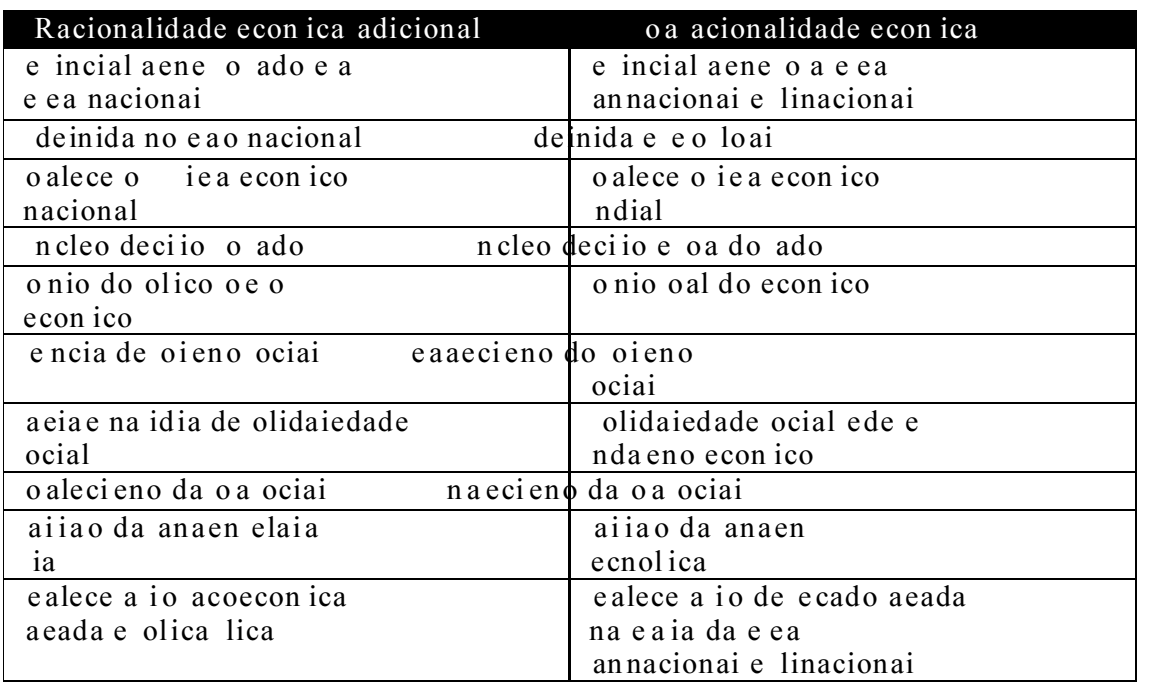

Tabela 1 - Antiga versus Nova racionalidade econômica (MELO NETO e FROES, 2001).

operacionalizar as novas transformações socioeconômicas na periferia é decorrente de uma "racionalidade social" a partir de uma "nova racionalidade econômica" (FURTADO apud MELO NETO e FROES, 2001).

Nesta nova racionalidade econômica, o Estado, "que era o principal gestor da racionalidade econômica cede lugar às empresas transnacionais e multinacionais, como principal agente da nova racionalidade econômica" (MELO NETO e FROES, 2001, p. 4). Com isso, os interesses empresariais sobrepõem os sociais, gerando uma legião de pessoas excluídas e incapazes de consumir os produtos criados pelas mesmas empresas que os geraram.

Além da gestão econômica, como sugerem os autores, a gestão social e a gestão cultural também passaram a ser, primordialmente, das empresas privadas e é missão da Responsabilidade Social Empresarial (RSE) tentar equacionar o desenvolvimento econômico, por meio de intervenções socioculturais nas comunidades pobres, em especial nas favelas ${ }^{4}$. Na tabela 1, apresentamos umas distinções sobre os modelos econômicos da racionalidade tradicional e da nova:

${ }^{4}$ Não abordaremos aqui as ações de RSE voltadas para os funcionários e seus familiares por entendermos que isso se relaciona bem mais com salários indiretos, que fazem parte das transformações dos interesses corporativos. 
Como se pode perceber, há de fato a emergência de novas lógicas de produção, ao mesmo tempo em que as políticas públicas oriundas do Estado perdem suas forças, para que a vontade das empresas sejam devidamente oficializadas. Assim, caberá ao Estado, por meio de seus parlamentos, normatizar a vontade das empresas, facilitando o livre fluxo do capital.

Essa racionalidade econômica é geradora de uma profunda exclusão social, principalmente com o aumento do desemprego - filiação social que, uma vez desfeita, gera uma cadeia de deficiências para o sujeito e para o grupo em que está inserido. Os principais fatores que interferem na diminuição das oportunidades de emprego são: a) o uso da tecnologia como substituição da mão-de-obra humana e b) a globalização das formas de produção, fazendo com que as empresas possam optar por produzir em regiões em que a força de trabalho custe menos, geralmente países pobres e com leis trabalhistas mais flexíveis ou que não são tão relevantes ao número de desempregados.

Esses dois fatores geram cadeias de exclusão. Primeiro, as empresas passam a exigir novas formações de mão-de-obra (teoria e prática), fazendo com que a) os trabalhadores menos preparados saiam do mercado e não consigam mais se reinserirem, o que leva, muitas vezes, a um aumento dos negócios informais; b) há uma precarização da vida de forma geral, não apenas pela ausência de recursos econômicos, mas também por falta de perspectiva, gerando um pessimismo social generalizado; c) os bolsões de pobreza se acentuam nos países ditos em desenvolvimento e os Estados dominados pelo nexo capitalista são cada vez mais inaptos para lidar com essa situação.

Com isso, as empresas promovem também uma racionalidade social, não para contrastar com o fluxo globablizante, mas para "atenuar seus efeitos e riscos sistêmicos", além de justificar a decisão pela racionalidade econômica, já descrita. Conforme Melo Neto e Froes (op cit) a racionalidade social das empresas consiste em:

a) elas são os principais agentes;

b) foco na comunidade e não na sociedade;

c) ênfase na prática da solidariedade empresarial e não local ou regional;

d) desenvolvimento da comunidade a partir das ações sociais empresariais;

e) a empresa como grande investidor social, e não o Estado ou a sociedade.

Pela Responsabilidade Social, as empresas se aproximam das comunidades e, ao fazê-lo, conseguem desenvolver mediações sociais favoráveis ao seu desenvolvimento. Os gastos de suas ações sociais, no entanto, são inseridos no valor dos produtos e cobrados de seus clientes, ou entram em condições de subvenção e são abatidos (pelo menos parte deles) em impostos devidos ao Estado. A forma mais prática desse ressarcimento, contudo, vem dos vários meios de promoção da empresa socialmente responsável junto à sociedade, por meio do Marketing, da Publicidade e do Jornalismo, entre outras áreas.

Embora tente afastar de sua atuação social a idéia de assistencialismo, a Responsabilidade Social Empresarial faz parte de uma longa tradição do "assistir", que envolve "um conjunto extraordinariamente diversificado de práticas que se inscrevem, entretanto, numa estrutura comum determinada pela 
existência de certas categorias de populações carentes e pela necessidade de atendê-las" (CASTEL, 1998). Os nomes, as justificativas e as formas de assistir podem mudar de acordo com cada momento histórico, mas, mesmo as maneiras contemporâneas, denominadas de inclusão social, só fazem sentido quando relacionadas aos altruísmos históricos constituídos desde a Idade Média (CASTEL, Idem).

Não vamos aqui fazer uma "genealogia" das formas assistencialistas $^{5}$, apenas pontuaremos algumas questões úteis ao nosso trabalho. A primeira consiste na importância que a socialização tem na elaboração das formas de assistir. A este respeito, Castel distingue "sociabilidade primária" de "socialidade". A sociabilidade primária relaciona a um "sistema de regras que ligam diretamente os membros de um grupo a partir de seu pertencimento familiar, de vizinhança, do trabalho e que tecem redes de interdependência sem mediação de instituições específicas" (Idem, p. 48). Nesse estágio, o sujeito está submetido a regras ancestrais de parentesco de modo sintético e normativo, que fazem com que assuma papéis que "permitem a transmissão das aprendizagens e a reprodução da existência social" (Idem).

Já socializar consiste em ampliar a "sociabilidade primária", integrando o sujeito em um grupo social mediado por instituições especializadas de diversas naturezas. Com isso, a sociedade consegue garantir que, ainda que o indivíduo venha a se "desfiliar" do "conjunto de relações de proximidade territorial" (parentesco, vizinhança e localidade), possa dispor de uma "família ampliada" e se "refiliar" socioculturalmente.

A categoria social do sujeito que que apresenta um trabalho de fôlego a respeito do tema, numa linguagem fácil e bastante agradável. depender de cada época. Pode ser vagabundo, pobre, proletário (aquele que só dispõe de sua força “de trabalho"), malandro, favelado, delinqüente ou excluído, entre outros.

As soluções para "refiliar" ou "incluir", como queiramos, também são diversificadas e vão desde a esmola dada pelos bem-sucedidos e caridosos, passando por variadas formas de assistência até chegar à inclusão social. Mas, assistir nunca deixou de ser uma fixação dos sujeitos, mesmos os estrangeiros, a alguma ordem ou lei local, de modo a garantir sua localização e, por conseguinte, o seu controle.

Os operadores das redes de assistência também sofrem mutações, mas duas características se mantêm: a) a sociedade civil divide, na maioria dos casos, com o Estado a responsabilidade de "cuidar" dos desfiliados; e b) quem se propõe a ajudar aos mais necessitados vê nisso uma forma de "elevação espiritual" (não por acaso, o Cristianismo é o grande amigo dos pobres).

Mas, à medida que a sociedade avança no tempo, há um afrouxamento tanto da sociabilidade primária quanto da socialidade, fazendo com que as instituições que já tinham uma certa preocupação com o cadastramento dos assistidos passassem a se profissionalizar cada vez mais e, assim, o hospital, o orfanato e a distribuição de esmolas tornam-se instituições "sociais". Castel chama esta especialização analogicamente de sociabilidade secundária, pela qual o social-assistencial "resulta de uma intervenção da sociedade sobre si mesma, diferentemente das instituições que existem em nome da tradição e do costume" (CASTEL, 1998, p. 57). Essas práticas de função protetora e integradora tornam-se, mais tarde, preventivas. Nessa corrente, surge o Terceiro Setor.

O Terceiro Setor "é composto de 
organizações estruturadas, localizadas fora do aparato formal do Estado, que não são destinadas a distribuir lucros auferidos com suas atividades entre os seus diretores ou entre um conjunto de acionistas" (SALAMON apud MELO NETO e FROES, op cit). O termo Terceiro Setor procura nomear os três principais grupos de atores responsáveis pelas forças econômicas, sociais e políticas de uma sociedade formadas por 1) Instituições Públicas, 2) Instituições Privadas e 3) Terceiro Setor ${ }^{6}$.

No Brasil, o Terceiro Setor se consolidou a partir dos anos noventa, justamente no momento em que se intensificou a ação do narcotráfico nas favelas e as cidades passaram a ficar mais ameaçadas e carentes de ações enérgicas e especializadas para a gestão do espaço público. Só a título de exemplo, a ONG Viva Rio surge, neste momento (1993), e se especializa nas mediações entre morro e asfalto, principalmente no que se refere à violência.

$\mathrm{Na}$ mesma época, surgem também os grupos voltados para a profissionalização de jovens por meio da arte, entre os quais estão o "Nós do Morro", criado em 1990, na favela Vidigal, e Afro Reggae, em 1993, em Vigário Geral.

Embora o Instituto Brasileiro de Análise Econômica (IBASE) tenha começado a atuar bem antes do grande investimento em ONGs, o modelo brasileiro de Terceiro Setor, em sua grande parte, foi importado dos Estados Unidos, principalmente no que se refere às tecnologias de gestão e formação de redes integrativas para complementaridade das ações, que ainda se encontram muito deficitárias, não apenas pelos modelos metodológicos ou legais, mas, sobretudo, pela dificuldade de compartilhamento financeiro entre as organizações. A nacionalização do modelo, no entanto, ganhou especial reforço com a promulgação da Lei 9.790/99, pelo Presidente da República, Fernando Henrique Cardoso, que institucionaliza a OSCIP (Organização Civil de Interesse Público), pela qual torna possível uma maior parceria entre os poderes públicos e a sociedade civil organizada.

Autogovernado, o Terceiro Setor remunera seus profissionais, principalmente os gestores e especialistas, mas grande parte de suas ações é desenvolvida pelo envolvimento de um significativo número de voluntários. Lançado no ano de 2000, o Portal do Voluntário ilustra bem as novas formas que o assistencialismo tomou a partir da Lei a que nos referimos acima. Revela, ainda, a profissionalização, a criação e integração de redes, com o uso das tecnologias da informação, principalmente a Internet, como instrumento de "atuação social" das empresas. Modelado pela "Comunitas" (criada em 1995), entidade gerida pela antropóloga e então Primeira Dama, Ruth Cardoso, o Portal do Voluntário consiste em "abrir caminhos para a ação voluntária: disponibilizar um ambiente de colaboração e discussões sobre voluntariado; e ser um ponto de referência e difusão de informação para o voluntariado" (AYRES, 2003).

Altamente carente de ações assistenciais das mais diversas naturezas, já que o atendimento de necessidades primárias como educação, trabalho e saúde, por parte do governo, é sofrível e profundamente lamentável, o Terceiro Setor encontrou no Brasil um terreno fértil para seu desenvolvimento. Sem fazer muita questão de diferenciar suas ações das governamentais, o que muitas vezes dá maior credibilidade junto à sociedade, as insti-
${ }^{6}$ Além das novas organizações sociais instituídas pelo Terceiro Setor, as que já existiam antes, inclusive os movimentos sociais de esquerda, são congregadas nele. 
tuições que o integram passaram a atuar com toda força, transformando-se em uma fonte de renda para muitos profissionais que estavam fora do mercado de trabalho ou queriam mudar de função. Com isso, outorga um processo de agenciamento privado da cultura, principalmente nas grandes metrópoles, sendo o Terceiro Setor o grande ator especializado em mediações socioculturais, referendado ${ }^{7}$ primordialmente pela iniciativa privada, por meio do fomento advindo dos programas de Responsabilidade Social Empresarial.

As estratégias sociais do Terceiro Setor, em grande parte, procuram conjugar política, cidadania e consumo. Para que haja essa conjugação, a cidadania deixa de ser relacionada ao acesso a direitos capazes de promover uma emancipação do sujeito para tornarse um espaço de exercício de consumo. Por isso, não é fortuita a força que a cultura periférica assume nesse universo, pois a inclusão social passa, cada vez mais, pela promoção de seus bens artísticos, orientada por essa nova racionalidade econômica sob os auspícios de seu porta-voz oficial, o Terceiro Setor.

\section{Abstract}

Reflecting on the mediation between the so-called peripheral culture and the market of symbolic goods is the main objective of this text. Hence, seek to build a reflection involving subject, products and speeches in the process of mediation between the "hill" and "asphalt", in an attempt to locate the best places of culture that are built between them. From this perspective, reflect on the popular culture in conjunction with the emergence of the so-called Third Sector in Brazil, to demonstrate the new settings of social mediators seeking to translate the excluded try to put them in the consumer market.

Key-words: Culture, Peripheral and Third Sector.

\section{Referências}

AYRES, Bruno. Informação, voluntariado e redes digitais. Orientadora: Profa. Dra. Sarita Albagli. Rio de Janeiro: UFRJ/ECO, 2003. Dissertação de Mestrado (Ciências da Informação).

BHABHA, Homi. O Local da Cultura. Belo Horizonte: Editora UFMG, 2005.

BAKHTIN, Mikhail. A Cultura Popular na Idade Média: o contexto de François Rabelais. São Paulo-Brasília: Edunb/Hucitec, 1993.

CASTEL, Robert. As metamorfoses da questão social: uma crônica do salário. Petrópolis, Vozes: 1998.

\section{CENTRO CULTURAL DOS CORREIOS. Catálogo da} exposição Estética da Periferia. Rio de Janeiro: Centro Cultural dos Correios, 2005.

MELO NETO, Francisco P. de Melo e FROES, César. Gestão da Responsabilidade Social corporativa: o caso brasileiro. Rio de Janeiro: Qualitymark, 2001.

PRYSTHON, Angela. Margens do Mundo: a periferia nas teorias do contemporâneo. Belo Horizonte: INTERCOM, 2003.

SODRE, Muniz. A verdade seduzida : por um conceito de cultura no Brasil. Rio de Janeiro: DP\&A, 2005.

ZALUAR, Alba e ALVITO, Marcos. Um século de favela. Rio de Janeiro: FGV, 2004.

YÚDICE, George. A Conveniência da Cultura. Belo Horizonte: Editora UFMG, 2004.

Editorial: 2003.

Data do recebimento: 12/02/2008

Data do aceite: 27/02/2008 